\title{
THE ARTICULAR DIVERSITY OF EARLY HAEMOCHROMATOSIS
}

\author{
J. M. DE JONGE-BOK, J. D. MACFARLANE
}

From University Hospital, Leiden

\begin{abstract}
This report details seven patients who had an arthropathy at presentation of their haemochromatosis. The spectrum ranged from arthralgia and normal radiographs to classic polyarthritis and the typical radiological triad of joint-space narrowing, sclerosis and cysts. Some atypical presentations are highlighted. An early diagnosis of haemochromatosis requires clinical suspicion; support can be obtained from serum iron studies, particularly saturation of iron-binding capacity and ferritin, and from biopsy of liver and/or synovium.
\end{abstract}

Arthropathy as a manifestation of haemochromatosis has been recognised for at least 20 years (Schumacher 1964 ; Kra, Hollingsworth and Finch 1965; Hamilton et al. 1968; Dymock et al. 1970) whereas arthropathy as a presentation of haemochromatosis has only been appreciated more recently (Gordon, Clarke and Ogryzlo 1974; Laborde et al. 1977; M'Seffar, Fornasier and Fox 1977; Bjelle et al. 1982; Askari et al. 1983; Hehlmann, Mohr and Walther 1984). There have been a few other reports suggesting iron overload as the cause of an arthropathy (Abbot and Gresham 1972; Sella and Goodman 1973; Fitzcharles et al. 1982). This report details seven patients, seen in an 18-month period, one of whom presented with a classic polyarthropathy, three with unusual joint manifestations and three with only arthralgia.

\section{CASE REPORTS}

Case 1. A man aged 69 had had arthralgia in his hands for six months, without swelling or morning stiffness. Blood studies showed increasing saturation with iron and a rising ferritin level. Radiographs of his hands were normal apart from a small cyst in the third metacarpophalangeal joint. He refused to have a liver biopsy.

Case 2. A woman aged 62 had a seronegative, symmetrical, peripheral polyarthritis, involving mainly the second and third metacarpophalangeal joints bilaterally, for several years before the onset of diabetes and abnormal liver function. A liver biopsy was diagnostic for haemochromatosis and her radiographs showed the classic triad of joint-space narrowing, cysts and sclerosis in the affected joints (Fig. 1: Table I). Case 3. A man aged 61 had had arthralgia in the right metacarpophalangeal joints for one year, associated with morning stiffness but

J. M. de Jonge-Bok, Rheumatologist

Bleuland Ziekenhuis, Gouda, The Netherlands.

J. D. Macfarlane, MRCP(UK), Rheumatologist

Department of Rheumatology, Staff Centre, Building I, C2Q University Hospital, PO Box 9600, 2300 RC Leiden, The Netherlands.

Correspondence should be sent to Dr J. D. Macfarlane.

(C) 1987 British Editorial Society of Bone and Joint Surgery $0301-620 \mathrm{X} / 87 / 1028 \$ 2.00$ not with swelling or impaired function. Radiographs showed extensive chondrocalcinosis which prompted blood studies and a liver biopsy showing fibrosis and marked accumulation of iron in parenchymal and Kupffer cells, thus confirming the diagnosis of haemochromatosis. Radiographs of the lumbar spine showed ligamentous calcification (Fig. 2).

Case 4. A man aged 58 had had two years of synovitis in the right second metacarpophalangeal joint and a hallux rigidus. The radiographic changes (joint-space narrowing, sclerosis and cysts) prompted iron studies (see Table I) and a liver biopsy, which showed a marked accumulation of iron in parenchymal cells but no fibrosis.

Case 5. A man aged 49 presented with fatigue, diminished libido and arthralgia in his hands, shoulders, knees and ankles. Routine physical

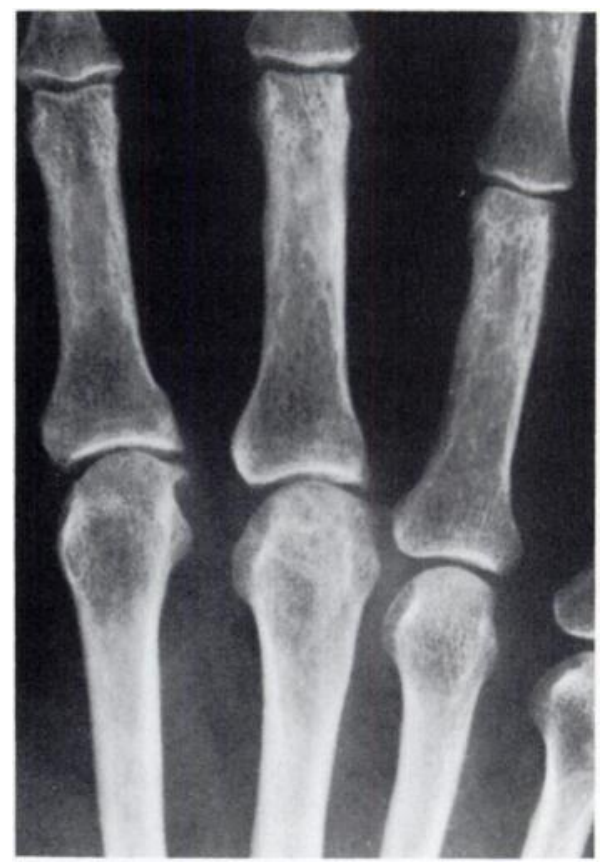

Fig. 1

Case 2. Detail from the radiograph of the hand showing joint-space narrowing, sclerosis, cysts and small osteophytes in the second and third metacarpophalangeal joints. 


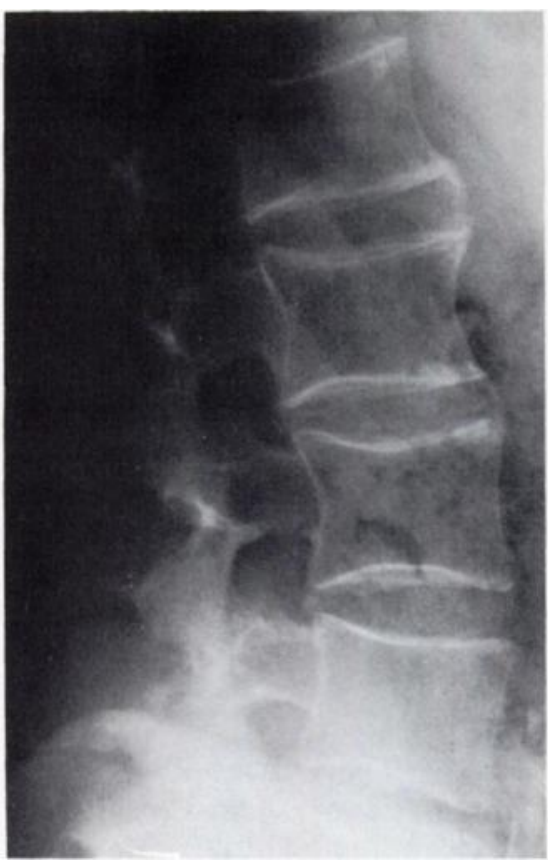

Fig. 2

Case 3. Radiograph of the lumbar spine showing ligamentous calcification.

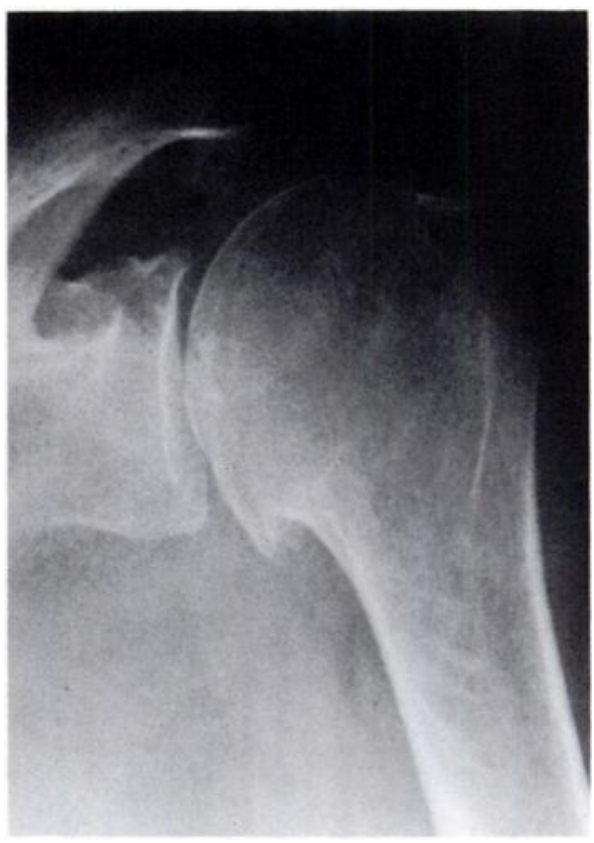

Fig. 3

Case 5. Radiograph of the left shoulder showing a deformed glenohumeral joint associated with cysts and osteophyte formation. examination was unremarkable apart from restricted movement of his left shoulder without synovitis. A glucose tolerance test was diabetic. A liver biopsy showed fibrosis and some cirrhotic nodules in addition to iron deposition. Radiographs of the shoulders showed deformation of the glenohumeral joints with osteophyte formation, sclerosis and cysts, more pronounced on the left (Fig. 3).

Case 6. A man aged 37 who had had arthralgia in his hands for two years presented with synovitis of the left ankle. His face was tinged a slate-grey colour and several proximal interphalangeal joints were tender but not swollen. Routine blood tests suggested a liver disorder and subsequent iron studies and a liver biopsy confirmed the diagnosis of haemochromatosis. Radiographs of his hands were normal but the ankle radiograph (Fig. 4) showed a cyst-like appearance and a probable defect in the lateral malleolus. At exploration no loose body was found but the hypertrophied synovium revealed marked iron deposition in the lining layer and in a few deeper macrophages. There was no giant-cel formation nor elaboration of histiocytes.

Case 7. A man aged 36 had had arthralgia affecting his hands, elbows, shoulders and knees for two years. On examination he had a mild slategrey skin colour, tenovaginitis of the flexor tendons in both hands and painful metacarpophalangeal joints without synovitis. Mild elevation of transaminase and a diabetic glucose tolerance test prompted serum ferritin estimation (see Table I). Radiographs showed a subtle progression in the second metacarpophalangeal joint in the course of two years. A liver biopsy revealed fibrosis with iron deposition in both parenchymal and Kupffer cells. A synovial biopsy from a metacarpophalangeal joint showed iron accumulation in only the synovial lining layer.

Table I. Clinical, radiological and laboratory data in seven patients with haemochromatosis and arthropathy

\begin{tabular}{|c|c|c|c|c|c|c|c|c|c|c|c|}
\hline \multirow[b]{2}{*}{ Case } & \multirow[b]{2}{*}{ Sex } & \multirow{2}{*}{$\begin{array}{l}\text { Age } \\
\text { (years) }\end{array}$} & \multirow{2}{*}{$\begin{array}{l}\text { Disease } \\
\text { interval } \\
\text { (years) }\end{array}$} & \multirow{2}{*}{$\begin{array}{l}\text { Joints } \\
\text { involved }\end{array}$} & \multirow[b]{2}{*}{ Synovitis } & \multirow[b]{2}{*}{ Symmetry } & \multicolumn{3}{|c|}{ Radiological findings } & \multirow{2}{*}{$\begin{array}{l}\text { Ferritina } \\
(\mu g / m l)\end{array}$} & \multirow{2}{*}{$\begin{array}{l}\text { Histological } \\
\text { proof }\end{array}$} \\
\hline & & & & & & & JSN & Cysts & Synovitis & & \\
\hline 1 & $\mathbf{M}$ & 69 & 0.5 & mcp 2 & - & - & - & + & - & 607 & ND \\
\hline 2 & $\mathbf{F}$ & 62 & 8 & $\begin{array}{l}\operatorname{mcp} 2+3 \\
\mathrm{mtp} 3\end{array}$ & + & + & $\begin{array}{l}+ \\
+\end{array}$ & + & $\begin{array}{l}+ \\
+\end{array}$ & ND & Liver \\
\hline 3 & $\mathbf{M}$ & 61 & 1 & mcp 2-5 & - & - & + & + & + & 3300 & Liver \\
\hline 4 & $\mathbf{M}$ & 58 & 2 & $\operatorname{mcp} 2$ & + & - & + & + & + & 1200 & Liver \\
\hline 5 & $\mathbf{M}$ & 49 & 1 & poly & - & + & + & + & + & 880 & Liver \\
\hline 6 & $\mathbf{M}$ & 37 & 2 & $\begin{array}{l}\text { ankle } \\
\text { pip }\end{array}$ & \pm & $\overline{+}$ & - & \pm & - & 1800 & $\begin{array}{l}\text { Liver } \\
\text { Synovium }\end{array}$ \\
\hline 7 & $\mathbf{M}$ & 36 & 2 & poly & $+b$ & + & - & + & + & 3800 & $\begin{array}{l}\text { Liver } \\
\text { Synovium }\end{array}$ \\
\hline
\end{tabular}

a Normal value of ferritin is less than $250 \mu \mathrm{g} / \mathrm{ml}$

bynovitis from flexor tendon sheath in hand

JSN, joint-space narrowing pip, proximal interphalangeal joint

ND, not done

mcp, metacarpophalangeal joint

mtp, metatarsophalangeal join poly, polyarthralgia-see text 


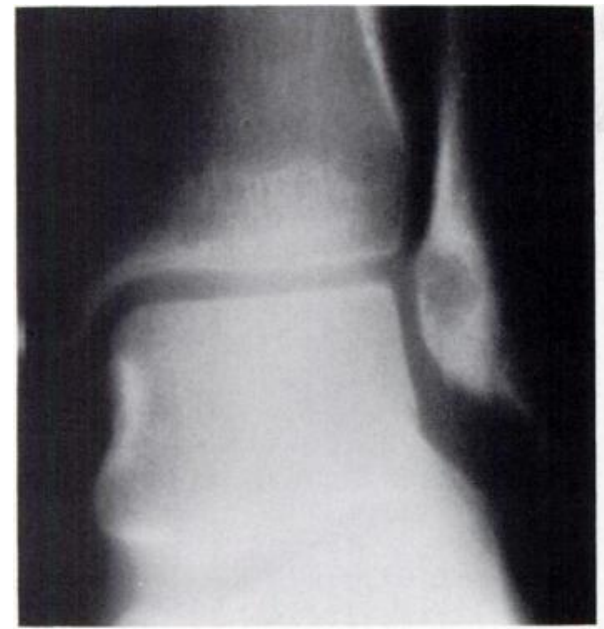

Fig. 4

Case 6. A planigram of the left ankle with an apparent defect in the medial side of the lateral malleolus.

Some clinical, radiological and laboratory details are summarised in Table I. The HLA profiles of six patients are presented in Table II. No patient had a positive Rose-Waaler, latex or antinuclear factor test. All had a low sedimentation rate and no other reason for the joint complaints. All patients except two (Cases 5 and 6 ) had received antiphlogistic therapy with only partial influence on their joint complaints. All except one (Case 1) have undergone regular phlebotomy with little variation in their generally mild and intermittent joint pains. The first patient is now symptom-free and receives no medication.

\section{DISCUSSION}

The classic arthropathy appearing in haemochromatosis is a polyarthropathy affecting the small joints of the hand, usually the second and third metacarpophalangeal joints, often symmetrically and associated with pain, bony swelling and mild limitation of movement (as in our

Table II. HLA profile in six patients

\begin{tabular}{llll}
\hline & \multicolumn{3}{l}{ HLA profile } \\
\cline { 2 - 4 } Case & A & B & CW \\
\hline $1^{*}$ & 3 & 7, W62(15); W6 & 3,7 \\
2 & 28 & W44(12); W60 & 3,7 \\
$3^{*}$ & 3 & 7,$27 ;$ W4, W6 & 2 \\
4 & 3,11 & W44(12), 17; W4 & 4,6 \\
$6^{*}$ & 3 & 7, W62(15); W6 & 3 \\
7 & 1, W24 & 7,$8 ;$ W6 & - \\
\hline
\end{tabular}

* The usual frequency of the combination A3, B7 in the Dutch population is $15 \%$ second patient). The course is usually progressive but major deformity and disability are rare (Hamilton et al. 1981); our fifth patient would appear to be an exception. This polyarthropathy can sometimes resemble rheumatoid arthritis and this is even more likely when tendon sheaths (Case 7) or bursae are involved or nodules are present (Bensen et al. 1978; Bjelle et al. 1982). Four patients had synovitis involving small joints of the hands, feet and ankle, and the flexor tendon sheath, whereas three patients had only arthralgia (Docquier et al. 1981), primarily in the hands (see Table I.) One patient rapidly developed functional limitation of the left shoulder without synovitis, and one presented with an ankle swelling.

The association of haemochromatosis with chondrocalcinosis is well founded (Hamilton et al. 1968; Dorfmann et al. 1969) and patients can suffer acute attacks (pseudogout) of pyrophosphate arthropathy (Hamilton et al. 1968; Dymock et al. 1970). The involvement of large joints such as the hip and shoulder may be related to this pyrophosphate deposition but good evidence is lacking. Extensive chondrocalcinosis is not invariably linked with either pseudogout or joint destruction. In our series chondrocalcinosis was found in only one patient compared with a $30 \%$ to $50 \%$ prevalence in established haemochromatosis found by Hamilton et al. (1968) and Dorfmann et al. (1969); in our patient this did not correlate with his joint symptoms. The same patient also had calcification in the lumbar spine, mainly in the ligaments (Bywaters, Hamilton and Williams 1971), thus simulating spondylitic disorders. There was no sacro-iliitis. How far these spinal changes are related to the presence of HLA-B27 antigen remains uncertain.

The clinical spectrum confronted in this series was broad, as was the radiological spectrum. The classic picture of joint-space narrowing with sclerosis and cysts was found in the metacarpophalangeal joints of four patients, in the proximal interphalangeal joints of two and the metatarsophalangeal joint in one. These changes were sometimes associated with small osteophyte formation. The classic triad was also discerned in the shoulder radiograph in Case 5, a relatively uncommon presentation.

The evidence for iron overload in haemochromatosis is not necessarily obvious. In this series only one patient clearly suffered from malaise and libido changes and one other had erythema palmaris of liver disease. Two had slate-grey skin colour and two had abnormal glucose tolerance tests. Support for the diagnosis of haemochromatosis came from the elevated serum iron, saturation of the iron-binding capacity and a raised ferritin. The desferrioxamine test for the urinary excretion of iron can be used to confirm iron overload. We have preferred to obtain histological proof from the liver (Cases 2 and 7) and from synovium (Cases 6 and 7). A synovial biopsy can confirm haemochromatosis as the cause of the arthropathy when iron deposition is 
confined to the synovial lining layer (Walker et al. 1972; Gordon et al. 1974; Bellamy 1980; Eulderink 1982; Schumacher 1982).

There is an association between haemochromatosis and HLA antigens (Schattenkirchner et al. 1981; Askari et al. 1983; De Greve et al. 1984; Hehlmann et al. 1984) and our series shows a preponderance of A3 and B7 (see Table II). A precise link with particular antigens has not been found but, within families, particular haplotypes can be linked to the presence of haemochromatosis, thereby enabling the identification of individuals at risk.

Therapy is essentially phlebotomy though this does not usually influence the joint complaints or prevent progression of the joint disease (Hamilton et al. 1968; Gordon et al. 1974; Docquier et al. 1981; Askari et al. 1983; Hehlmann et al. 1984) except possibly in early disease (Askari et al. 1983; De Greve et al. 1984). Analgesic and antiphlogistic drugs can be effective and destroyed joints can be treated by osteotomy or arthroplasty (Rand and Sim 1981; Askari et al. 1983). The mortality is higher in the cirrhotic patients (especially if diabetic) and in those whose iron stores have not been reduced by 18 months of regular venesection (Niederau et al. 1985).

The patients presented here indicate the wide spectrum of clinical and radiological changes occurring in haemochromatosis. We confirm the male preponderance and wonder whether women are in part protected from iron overload by premenopausal loss of iron. We agree with other authors (M'Seffar et al. 1977; Bellamy 1980) that a high index of suspicion is warranted by various specialists, and in particular by orthopaedic surgeons who may be confronted with unusual arthropathies. Measurement of the serum ferritin (or even liver biopsy) helps in the detection of haemochromatosis, especially if there is only arthralgia (Askari et al. 1983) or a normal radiograph (Mall and Zander 1980). Orthopaedic surgeons and pathologists can greatly assist in the identification of the typical synovial histology (Bellamy 1980). It should be stressed that early diagnosis and therapy improves life expectancy (Niederau et al. 1985).

The authors are indebted to Professor A. Cats for his constructive criticism and to Mrs J. Ravenbergen for secretarial assistance.

\section{REFERENCES}

Abbot DF, Gresham GA. Arthropathy in transfusional siderosis. $\mathrm{Br}$ Med J 1972;i:418-9.

Askari AD, Muir WA, Rosner IA, Moskowitz RW, McLaren GD, Braun WE. Arthritis of hemochromatosis: clinical spectrum, relation to histocompatibility antigens, and effectiveness of early phlebotomy. Am J Med 1983;75:957-65.
Bellamy RE. The orthopedic surgeon and hemochromatosis. Orthopedics 1980;3(5):419-23.

Bensen WG, Laskin GA, Little HA, Fam AG. Hemochromatotic arthropathy mimicking rheumatoid arthritis: a case with subcutaneous nodules, tenosynovitis and bursitis. Arthritis Rheum $1978 ; 21: 844-8$.

Bjelle A, Hassler O, Hägg E, Lindström G. Arthropathy in haemochromatosis: clinical survey and a morphological study of synovial and synovial sheath membranes. Akt Rheumatol 1982;7:148-53.

Bywaters EGL, Hamilton EBD, Williams R. The spine in idiopathic haemochromatosis. Ann Rheum Dis 1971;30:453-65.

De Greve JL, Verbruggen LA, Schallier D, Van Camp B. Idiopathic familial hemochromatosis: limited disease extent with prolonged survival and arthritis. Clin Rheumatol 1984;3(1):61-6.

Docquier Ch, Henrion J, Heller F, Tellier E, Lebacq E. L'arthropathie de l'hémochromatose idiopathique: a propos de 7 observations. Acta Rhumatol 1981;5:182-96 (Eng. Abstr.).

Dorfmann H, Solnica JH, Di Menza C, De Sèze S. Les arthropathies des hémochromatoses: résultats d'une enquête prospective portant sur 54 malades. Sem Hop Paris 1969;45:516-23.

Dymock IW, Hamilton EB, Laws JW, Williams R. Arthropathy of haemochromatosis: clinical and radiological analysis of 63 patients with iron overload. Ann Rheum Dis 1970;29:469-76.

Eulderink F. The synovial biopsy. In: Berry $\mathrm{CL}$, ed. Bone and joint disease. Current topics in pathology, vol. 71. Berlin etc: Springer Verlag, 1982:25-72.

Fitzcharles MA, Kirwan JR, Colvin BT, Currey HL. Sideroblastic anaemia with iron overload presenting as an arthropathy. Ann Rheum Dis 1982;41:97-9.

Gordon DA, Clarke PV, Ogryzlo MA. The chondrocalcific arthropathy of iron overload: relationship to hemochromatosis. Arch Intern Med 1974;134:21-8.

Hamilton E. Williams R, Barlow KA, Smith PM. The arthropathy of idiopathic haemochromatosis. $Q J$ Med 1968;NS37:171-82.

Hamilton EBD, Bomford AB, Laws JW, Williams R. The natural history of arthritis in idiopathic haemochromatosis: progression of the clinical and radiological features over ten years. $Q J$ Med $1981 ;$ NS50:321-9.

Hehimann R, Mohr C, Walther B. Arthropathie als Frühsymptom der Hämochromatose: literaturübersicht und Bericht über 7 Fälle. Schweiz Med Wschr 1984;114:583-90.

Kra SJ, Hollingsworth JW, Finch SC. Arthritis with synovial iron deposition in a patient with hemochromatosis. New Engl J Med $1965 ; 272: 1268-71$.

Laborde JM, Green DL, Askari AD, Muir A. Arthritis in hemochromatosis: a case report. J Bone Joint Surg [Am] 1977;59-A:1103-7.

Mall K, Zander W. Arthropathie bei Hämochromatose. ROEFO 1980;132(4):441-6 [Eng. Abstr].

M'Seffar A, Fornasier VL, Fox IH. Arthropathy as the major clinical indicator of occult iron storage disease. JAMA 1977;238:1825-8.

Niederau C, Fischer R, Sonnenberg A, Stremmel W, Trampisch HJ, Strohmeyer G. Survival and causes of death in cirrhotic and in noncirrhotic patients with primary hemochromatosis. $N$ Engl $J$ Med 1985;313:1256-62.

Rand JA, Sim FH. Total shoulder arthroplasty for the arthropathy of hemochromatosis: a case report. Orthopedics 1981;4(6):658-60.

Schattenkirchner M, Fischbacher L, Giebner U, Albert ED. Die Arthropathie bei der idiopathischen Hämochromatose (I.H.). Verh Dtsch Ges Rheumatol 1981 ;7:414-9.

Schumacher HR Jr. Hemochromatosis and arthritis. Arthritis Rheum 1964;7:41-50.

Schumacher HR. Articular cartilage in the degenerative arthropathy of hemochromatosis. Arthritis Rheum 1982;25:1460-8.

Sella EJ, Goodman AG. Arthropathy secondary to transfusion hemochromatosis. J Bone Joint Surg [Am] 1973;55-A:1077-81.

Walker RJ, Dymock IW, Ansell ID, Hamilton EBD, Williams R. Synovial biopsy in haemochromatosis arthropathy: histological findings and iron deposition in relation to total body iron overload. Ann Rheum Dis 1972;31:98-102. 